PROF. JORGE J CASAL (Orcid ID : 0000-0001-6525-8414)

Article type : MS - Regular Manuscript

\title{
Functional convergence of growth responses to shade and warmth in Arabidopsis
}

\section{Sofía Romero-Montepaone ${ }^{1}$, Romina Sellaro', Carlos Esteban Hernando², Cecilia Costigliolo-Rojas², Luciana Bianchimano², Edmundo L. Ploschuk²,} Marcelo J. Yanovsky², Jorge J. Casal ${ }^{1,2}$

${ }^{1}$ Universidad de Buenos Aires, Consejo Nacional de Investigaciones Científicas y Técnicas (CONICET), Instituto de Investigaciones Fisiológicas y Ecológicas Vinculadas a la Agricultura (IFEVA), Facultad de Agronomía, C1417DSE, Buenos Aires, Argentina.

2 Fundación Instituto Leloir, Instituto de Investigaciones Bioquímicas de Buenos Aires, CONICET, C1405 BWE, Buenos Aires, Argentina.

${ }^{3}$ Universidad de Buenos Aires, Facultad de Agronomía, Cátedra de Cultivos Industriales, Av. San Martín 4453, C1417DSE, Buenos Aires, Argentina.

Author for correspondence:

Tel: 5411 5287-0110

This article has been accepted for publication and undergone full peer review but has not been through the copyediting, typesetting, pagination and proofreading process, which may lead to differences between this version and the Version of Record. Please cite this article as doi: 10.1111/NPH.17430

This article is protected by copyright. All rights reserved 
Email: casal@agro.uba.ar

Received: 25 November 2020

Accepted: 15 April 2021

ORCID

Sofía Romero-Montepaone: 0000-0003-1957-0348

Romina Sellaro: 0000-0002-4412-1352

Carlos Esteban Hernando: 0000-0002-7459-2083

Cecilia Costigliolo-Rojas: 0000-0003-3075-8464

Luciana Bianchimano: 0000-0002-6216-8373

Edmundo L. Ploschuk: 0000-0002-1765-8816

Marcelo J. Yanovsky: 0000-0002-1890-0571

Jorge J. Casal: 0000-0001-6525-8414

This article is protected by copyright. All rights reserved 


\section{Summary}

- Shade and warmth promote the growth of the stem but the degree of mechanistic convergence and functional association between these responses is not clear.

- We analysed the quantitative impact of mutations and natural genetic variation on the hypocotyl growth responses of Arabidopsis thaliana to shade and warmth, the relationship between the abundance of PHYTOCHROME INTERACTING FACTOR 4 (PIF4) and growth stimulation by shade or warmth, the effects of both cues on the transcriptome and the consequences of warm temperature on carbon balance.

- Growth responses to shade and warmth showed strong genetic linkage and similar dependence on PIF4 levels. Temperature increased growth and phototropism even within a range where damage by extreme high temperatures is unlikely to occur in nature. Both cues enhanced the expression of growth-related genes and reduced the expression of photosynthetic genes. However, only warmth enhanced the expression of genes involved in responses to heat. Warm temperatures substantially increased the amount of light required to compensate for the daily carbon dioxide balance.

- We propose that the main ecological function of hypocotyl growth responses to warmth is to increase the access of shaded photosynthetic organs to light, which implies functional convergence with shade avoidance.

Key words: Arabidopsis thaliana, carbon balance, PHYTOCHROME INTERACTING FACTOR (PIF), shade avoidance, thermomorphogenesis. 


\section{Introduction}

Mutual shading among plants reduces the amount of photosynthetically active radiation received by each individual, compromising seed production (Poorter et al., 2019) and hence fitness. Plants exposed to light cues that indicate the presence of nearby non-shading neighbours or the occurrence of actual shade, exhibit shade-avoidance responses, which in Arabidopsis thaliana include the promotion of hypocotyl and petiole growth and the elevation of the leaves (hyponasty) (Casal, 2013; Ballaré \& Pierik, 2017). These responses place the photosynthetic organs (cotyledons, leaf lamina) at a higher stratum of the canopy, where strong shade is less likely.

Exposure to temperatures above $30^{\circ} \mathrm{C}$ causes reductions in plant growth and foliar damage imposing severely impaired fitness to $A$. thaliana plants (Lippmann et al., 2019). Warm temperatures below those extremes promote thermomorphogenic responses, such as hypocotyl and petiole growth and leaf hyponasty (Quint et al., 2016; Casal \& Balasubramanian, 2019). These responses increase evaporative cooling capacity and could therefore reduce the chances of heat damage (Crawford et al., 2012; Bridge et al., 2013). In other words, neighbour cues provided by the light environment and temperature cues indicative of the likely occurrence of heat could converge on similar growth responses but for different ecological goals.

In addition to the similarities in growth patterns, shade avoidance and thermomorphogenesis share molecular players. PHYTOCHROME INTERACTING FACTORS 4 (PIF4) (Lorrain et al., 2008; Koini et al., 2009; Franklin et al., 2011; Hornitschek et al., 2012) and (PIF7) (Li et al., 2012; Huang et al., 2018; Fiorucci et al., 2020; Chung et al., 2020) are bHLH transcription factors that increase their abundance in response to cues from neighbours or warm temperatures. They bind to the promoters of YUCCA genes enhancing their expression and elevating the levels of auxin (Li et al., 2012; Hornitschek et al., 2012; Chung et al., 2020). Auxin is produced mainly in the cotyledons and travels to the hypocotyl to promote cell expansion and elongation (Procko et al., 2014; Bellstaedt et al., 2019). PIF4 has also a role in the hypocotyl, where it promotes growth, particularly when auxin levels have already declined under persistent shade (Pucciariello et al., 2018). CONSTITUTIVE PHOTOMORPHOGENIC 1 (COP1) is an E3 ligase (Lau \& Deng, 2012). Both shade and warmth enhance the nuclear abundance of COP1 (Pacín et al., 2013; Park et al., 2017) favouring the contact between COP1 and the negative regulators of PIFs in the nucleus (Pacín et al., 2016; Park et al., 2017; Blanco-Touriñán et al., 2020). Phytochrome B (phyB) is one of the most influential photosensory receptors (Smith, 2000). When the tissues are exposed to a high proportion of red light 
characteristic of sunlight phyB is highly active and inhibits shade-avoidance responses. The presence of green neighbours that reflect or transmit more far-red light than red light reduces phyB via photochemical reactions (Sellaro et al., 2019). Warm temperatures also reduce phyB activity but by thermal reversion (Jung et al., 2016; Legris et al., 2016). Low red / far-red ratios reduce phyB activity and hence increase PIF4 (Lorrain et al., 2008), PIF7 (Huang et al., 2018) and COP1 activity (Pacín et al., 2013), allowing hypocotyl and petiole growth and leaf hyponasty to proceed.

In addition to the shared sensing-signalling pathway, shade and warmth cues have specific entry points. Cryptochromes perceive the low blue-light levels of shade (Sellaro et al., 2010; Keller et al., 2011) and their action converges with that of phyB on PIFs (Pedmale et al., 2010; Ma et al., 2016) and COP1 (Lau et al., 2019). Warm temperatures are also sensed by an RNA hairpin within the 5' untranslated region of PIF7 transcript, which leads to enhanced translation and increased PIF7 protein abundance in the warmth (Chung et al., 2020). A third sensor of temperature is EARLY FLOWERING 3 (ELF3), which contains a polyglutamine repeat embedded within a predicted prion domain and shifts between active and inactive states via phase transition (Jung et al., 2020). ELF3 is a component of the EVENING COMPLEX, which shows reduced binding to DNA in the warmth (Silva et al., 2020). ELF3 is a repressor of PIF4 and PIF5 expression (Nusinow et al., 2011; Ezer et al., 2017). Furthermore, ELONGATED HYPOCOTYL 5 (HY5) and LONG HYPOCOTYL IN FAR-RED (HFR1) are negative regulators of PIFs (Hornitschek et al., 2009; Delker et al., 2014; Johansson et al., 2014) and both are targets of COP1 (Osterlund et al., 2000; Duek et al., 2004). Yet, HY5 decreases with warmth and not with shade and HFR1 decreases with shade but not with warmth (Foreman et al., 2011; Pacín et al., 2016; Park et al., 2017). HISTONE DEACETYLASE 9 (HDA9) facilitates binding of PIF4 to auxin synthesis genes and promotion of hypocotyl growth at warm temperature, but the growth response to neighbour cues does not require HDA9 (Van Der Woude et al., 2019).

The functional significance of the convergence and divergence of light and temperature information through shared and specific molecular players is not clear. To address this issue, we analysed the extent of the convergence in terms of quantitative impact of different signalling components in both responses, the differences and similarities in the associated changes in transcriptome and the physiological implications.

\section{Materials and Methods}




\section{Plant material}

Seeds of Arabidopsis thaliana were sown on $0.8 \%$ agar-water in clear plastic boxes $(8 \times 5 \times 2 \mathrm{~cm})$, stratified 5-7 d at $5{ }^{\circ} \mathrm{C}$ in darkness and transferred to a growth room at $22^{\circ} \mathrm{C}$ with a photoperiod of 10 $\mathrm{h}$ of $100 \mu \mathrm{molm}^{-2} \mathrm{~s}^{-1}$ of white light $(400-700 \mathrm{~nm})$ provided by a mixture of fluorescent and halogen lamps $(\mathrm{red} /$ far-red ratio $=1.1)$. Except for the experiments aimed at analysing natural variation, we used the background Columbia for all genotypes. The mutants, transgenic lines and accessions are listed in Table S1.

\section{Light and temperature treatments under controlled conditions}

The seedlings were transferred to the treatment conditions at the beginning of the fourth day. Treatments involved all possible combinations of three temperatures $\left(14^{\circ} \mathrm{C}, 20^{\circ} \mathrm{C}\right.$ and $\left.28^{\circ} \mathrm{C}\right)$ and four different light conditions (white light simulating sunlight, mild shade, moderate shade or deep shade). The red / far-red ratios were: 1.1, 0.8, 0.4 and 0.1 and the irradiances between 400 and $700 \mathrm{~nm}$ were $100,70,48$ and $18 \mu \mathrm{mol} . \mathrm{m}^{-2} . \mathrm{s}^{-1}$, respectively. Some experiments did not include the conditions with $14^{\circ} \mathrm{C}$ and/or mild and moderate shade. The light sources and spectra were as described (Romero-Montepaone et al., 2020).

\section{Field experiments}

The seedlings were transferred to the experimental field of Facultad de Agronomía, University of Buenos Aires (latitude: 34.5914, longitude: 58.4798), at the beginning of the fourth day in ten different sowing dates between June (winter) and February (summer). In the field, the plants were exposed to unfiltered sunlight or shade from either a short or a tall grass canopy. The average red / far-red ratios across experiments were 1.1, 0.6 and 0.2 , respectively. Light and temperature conditions inside the boxes were recorded as described (Romero-Montepaone et al., 2020).

\section{Hypocotyl and cotyledon growth}

In hypocotyl-growth experiments, the seedlings were grown parallel to the agar surface and photographed from the side at the beginning and at the end of the photoperiod of the fourth day. For cotyledon expansion, the seedlings were grown normal to the agar surface and photographed from the top at the beginning and at the end of the photoperiod of the fourth day. Hypocotyl length and cotyledon area were measured using image processing software (Adobe Photoshop CC) and 
increments during the $10 \mathrm{~h}$ of the photoperiod were calculated to obtain hourly rates. Compared to the control at $20^{\circ} \mathrm{C}, 28^{\circ} \mathrm{C}$ enhanced the rate of hypocotyl extension growth but not the rate of cotyledon expansion (Fig. S1), confirming that the criterion of specificity in the response to temperature between different organs is fulfilled.

\section{Calculation of the impact of different mutations on the responses to shade and to warmth}

We define the impact of a given mutation on the hypocotyl growth response as the ratio between the growth of such mutant and that of the wild type exposed to the same conditions. The impact is lower than 1 when the mutation reduces growth and higher than 1 when the mutation increases growth. We used the stepwise mode of multiple linear regression of Statistix to calculate the impact of different mutations on the response to shade and on the response to warmth. The response variable was the growth rate of the mutant. The explanatory variables were: a) the rate of growth of the wild type under the same light and temperature conditions, b) the growth rate of the wild type under the same light conditions, but under control temperature conditions, and c) the growth rate of the wild type under the same temperature conditions but under control light conditions. These explanatory variables yielded slopes $a, b$ and $c$, respectively. Depending on the mutants slopes $b$ and/or $c$ were excluded (not statistically significant) by the stepwise analysis and its value was therefore null. The impact of the mutation on the response to shade is the sum of slopes $a$ and $b$. The impact of the mutation on the response to warmth is the sum of slopes a and $c$. To illustrate these concepts, we applied the analysis to a set of imaginary mutants for which we defined a priori their impacts on the response to shade and on the response to warmth (Fig. S2).

\section{Confocal microscopy}

We used a LSM5 Pascal laser-scanning microscope (Zeiss) with a water immersion objective lens (C-Apochromat 40x / 1,2; Zeiss). For chloroplast visualization, probes were excited with a He-Ne laser $(\lambda=543 \mathrm{~nm})$ and fluorescence was detected using an LP560 filter. For visualization of GFP/YFP fusion proteins and DII-VENUS, probes were excited with an Argon laser $(\lambda=488 \mathrm{~nm})$ and fluorescence was detected using a BP 505-530 and BP 505-570 filter respectively. Images were recorded $5 \mathrm{~h}$ after the beginning of the photoperiod when the seedlings were exposed to the different light/shade and temperature conditions. 


\section{Luminometer readings}

Luciferase (LUC) activity was detected with a Centro LB 960 (Berthold) luminometer. Transgenic seedlings bearing the LUC reporter were incubated with $20 \mu \mathrm{L}$ of $0.5 \mathrm{mM}$ D-luciferin per well twentyfour hours before starting to record luciferase activity. LUC activity was recorded $5 \mathrm{~h}$ after the beginning of the photoperiod when the seedlings were exposed to the different light/shade and temperature conditions.

\section{RNA sequencing}

Total RNA was extracted from three biological replicate samples with RNeasy Plant Mini Kit (QIAGEN) following the manufacturer's protocols. To estimate the concentration and quality of samples, NanoDrop 2000c (Thermo Scientific) and the Agilent 2100 Bioanalyzer (Agilent Technologies) with the Agilent RNA 6000 Nano Kit were used respectively. Libraries were prepared following the TruSeq RNA Sample Preparation Guide (Illumina). Briefly, $3 \mu \mathrm{g}$ of total RNA was polyApurified and fragmented, first-strand cDNA synthesized by reverse transcriptase (SuperScript II, Invitrogen) using random hexamers. This was followed by RNA degradation and second-strand cDNA synthesis. End repair process and addition of a single A nucleotide to the 3 ' ends allowed ligation of multiple indexing adapters. Then, an enrichment step of 12 cycles of PCR was performed. Library validation included size and purity assessment with the Agilent 2100 Bioanalyzer and the Agilent DNA1000 kit (Agilent Technologies). Samples were pooled to create 6 multiplexed DNA libraries, which were pair-end sequenced with an Illumina HiSeq 1500 at INDEAR Argentina, providing 100-bp pair-end reads. Sequencing data are available at Gene Expression Omnibus, accession number: GSE162240.

\section{Processing of RNA sequencing reads}

Sequence reads were mapped to Arabidopsis thaliana TAIR10 (Lamesch et al., 2012) genome using TopHat v2.1.1 (Trapnell et al., 2009) with default parameters, except of maximum intron length set at 5,000 . Count tables for different feature levels were obtained from bam files using custom $R$ scripts and considering TAIR10 transcriptome.

\section{Differential gene expression analysis}


Before differential expression analysis, we decided to discard genes with fewer than 10 reads on average per condition. Counts were normalised and transformed to continuous data using the Voom function (Law et al., 2014) in R (R Core Team, 2017). By using ANOVA with light or shade and $20^{\circ} \mathrm{C}$ or $28^{\circ} \mathrm{C}$ as main effects we identified 2225 genes with $q$ values (Storey \& Tibshirani, 2003) of treatments lower than 0.05 (Table S2). These genes were then grouped according to the significance $(p<0.05)$ of the main effects of light and/or temperature treatments.

\section{Functional category enrichment analysis}

Functional categories defined by gene-ontology (GO) terms associated with the gene clusters were identified by using the BioMaps tool from the virtual plant software (http://virtualplant.bio.nyu.edu/cgibin/vpweb). This tool determines which functional categories are statistically over represented in particular lists of genes compared to the entire genome (Katari et al., 2010). For different functional categories we calculated the representation factor, which is the ratio between the frequency of genes of that category in the cluster (observed frequency) and the frequency of genes of that category among the genes expressed in our experiment (expected frequency). Representation factors $>1$ and $<1$ indicate more and less overlap than expected by chance, respectively. The probability of finding an overlap simply by chance was determined using the hypergeometric probability formula (Table S3). We followed a similar procedure for metabolic pathways from AraCyc (Mueller et al., 2003).

\section{Enrichment of binding motifs}

We explored the similarities in transcription factor binding patterns among the different gene expression clusters. We calculated the relative enrichment of binding target genes by transcription factors as the ratio between the proportion of targets in the cluster and the proportion of targets in the genome (Table S4a). We used Plantpan3.0 (http://PlantPAN.itps.ncku.edu.tw, Chow et al., 2019) for the analysis of similarity because it is based on chip-seq data. After standardisation (subtraction of the mean followed by division by the standard deviation of each transcription factor), we used Pvclust (https://cran.r-project.org/web/packages/pvclust/index.html, Suzuki \& Shimodaira, 2006) for hierarchical clustering and assessment of cluster uncertainty. To investigate the specific overrepresented transcription binding sites in each expression cluster we used PlantRegMap (http://plantregmap.gao-lab.org), which is based on an extended transcription factor repertoire (Tian et al., 2020). 


\section{Meta-analysis of the gene-expression response to temperature}

To investigate the range of response to temperature of the three clusters of genes with expression enhanced by temperature identified in our RNA sequencing analysis we conducted a meta-analysis of published data. We incorporated experiments where $A$. thaliana seedlings were grown at $22^{\circ} \mathrm{C}$ or $23^{\circ} \mathrm{C}$ and transferred to $4^{\circ} \mathrm{C}$ (Yang et al., 2019), $10^{\circ} \mathrm{C}$ (Schlaen et al., 2015), $27^{\circ} \mathrm{C}$ (Cortijo et al., 2017; Tasset et al., 2018), $30^{\circ} \mathrm{C}$ (Grinevich et al., 2019) or $37^{\circ} \mathrm{C}$ (Zhang et al., 2017). Counts were normalised and transformed to continuous data using the Voom function (Law et al., 2014) in R (R Core Team, 2017). Log-fold-changes of expression were calculated for each gene and experiment by subtracting the average value at $22^{\circ} \mathrm{C}$ or $23^{\circ} \mathrm{C}$ (depending on which one of these temperatures was used in the experiment). We included the genes of these clusters that showed expression in at least three continuous temperatures (to ensure patterns supported by multiple experiments) and a $q$ value $<0.01$ in ANOVA using the different temperatures as treatments.

\section{Phototropic response of the hypocotyl}

The seedlings were grown parallel to the agar surface in plastic boxes with all their sides, except the top, covered with black plastic to force upright growth. At the beginning of the fourth day the black covers were removed and the seedlings were irradiated with the white light source $\left(100 \mu \mathrm{molm}^{-2} \mathrm{~s}^{-1}\right)$ from one side (normally to the vertical hypocotyl) rather than from the top, at three different temperatures $\left(14^{\circ} \mathrm{C}, 20^{\circ} \mathrm{C}, 28^{\circ} \mathrm{C}\right)$. The seedlings were photographed from the side at the beginning and at the end of the photoperiod of the fourth day. The angle of the hypocotyl with respect to the vertical position was measured with image processing software (Adobe Photoshop CC).

\section{Net carbon dioxide exchange}

We used a portable gas-exchange system (LI-COR 6400, LI-COR) to measure net $\mathrm{CO}_{2}$-exchange $\left(\mu \mathrm{mol} \mathrm{CO}_{2} \mathrm{~m}^{-2} \mathrm{~s}{ }^{-1}\right)$. This equipment automatically controls airflow $\left(300 \mu \mathrm{mol} \mathrm{s}^{-1}\right)$ and $\mathrm{CO}_{2}$ concentration in the reference cell $\left(\mathrm{CO}_{2} \mathrm{R}, 400 \mathrm{ppm}\right)$. To measure net $\mathrm{CO}_{2}$-exchange of entire seedlings at the hypocotyl stage we transferred these seedlings on their agar substrate to a custombuilt cylindrical chamber $\left(20 \mathrm{~cm}^{3}\right)$ connected to the gas-exchange system under $900 \mu \mathrm{mol} \mathrm{m}^{-2} \mathrm{~s}^{-1}$ provided by an external source and at night. For young, fully expanded rosette leaves we used the LI-COR 6400-40 leaf chamber with the 6400-02B LED light source (photosinthetically active 
radiation: $2000,1500,1000,750,500,400,300,200,100,50$ and/or $0 \mu \mathrm{mol} \mathrm{m}^{-2} \mathrm{~s}^{-1}$ ). We performed a match calibration before each measurement, in order to maximize accuracy. We grew the plants at $20^{\circ} \mathrm{C}$ and either transferred them to $28^{\circ} \mathrm{C} 1 \mathrm{~h}$ before measurements or left them as $20^{\circ} \mathrm{C}$ controls. We set the block temperature of the chamber to the corresponding temperature.

\section{Probability of occurrence of heat shocks}

We downloaded from NOAA (National Centers for Environmental Information, https://www.ncdc.noaa.gov/cdo-web/confirmation) information about daily minimum and maximum temperatures in 20 locations (seven in Europe, four in Asia, four in Africa, three in America and two in Oceania) between 1 January and 31 December, 2019. We used minimum and maximum temperatures to calculate the average and defined the occurrence of a heat shock when the maximum temperature reached $35^{\circ} \mathrm{C}$ or more. We then plotted the frequency of occurrence of heat shocks as a function of the average temperature during the previous four days.

\section{Results}

\section{Similar impact of mutations on the responses to shade or warmth}

We compared the quantitative impact of mutations in key genes on the responses of light-grown seedlings of $A$. thaliana to shade and to warmth. Under controlled conditions, we exposed the seedlings to all possible combinations of three temperatures $\left(14^{\circ} \mathrm{C}, 20^{\circ} \mathrm{C}\right.$ and $\left.28^{\circ} \mathrm{C}\right)$ and four light environments (simulating sunlight, mild shade, moderate shade or deep shade). In the field, we exposed the seedlings to three light conditions (sunlight, shade by a short grass canopy and shade by a tall grass canopy) and the experiment was repeated on 10 different occasions to generate a range of temperatures. We then used multiple regression of the growth rate of each mutant (pooled data from controlled and field conditions, Fig. 1a) to calculate the impact of the mutations on the response to shade and on the response to warmth (Fig. S2). These impacts assumed values either lower or higher than 1 depending on whether the mutation respectively reduced or increased the growth rate compared to the wild type. In Fig. $1 \mathrm{~b}$ we plot the impact on the response to shade against the impact on the response to warmth. Most mutants show negligible departure from the 1:1 line, indicating that different mutations have quantitatively similar impact on the responses to shade or warmth. When the growth of each mutant is plotted against that of the wild type under the same 
conditions, a single line shared by the different light and temperature environments accounts for most of the impact of each mutant with relatively small biases caused specifically by either light or temperature conditions (Fig. 1a). The exception is elf3. The latter mutation enhanced the response to shade much more than the response to warmth (Fig. 1b). In fact, in the case of elf3, there are more points belonging to deep shade above than below the solid line shared by the responses to both environmental cues (Fig. 1a).

\section{Correlation between PIF4 abundance and growth}

Since PIF4 is required for both shade and temperature responses, we investigated the relationship between PIF4 protein abundance and growth. For this purpose, we measured the fluorescence driven by the pPIF4:PIF4-GFP transgene in epidermal and sub-epidermal hypocotyl cells (Fig. 2a, S3) and the luminescence driven by the pPIF4:PIF4-LUC transgene in entire seedlings (Fig. 2b). We observed the expected increases with shade and with warmth (Fig. 2a-b) (Lorrain et al., 2008; Koini et al., 2009; Legris et al., 2017). Growth rate related to PIF4 protein levels without major biases caused by specific light or temperature conditions (Fig. 2c-d). This would account for the similar impact of the pif4 mutation on both responses (Fig. 1).

\section{Similar impact of natural variation on the responses to shade or warmth}

We compared the quantitative impact of natural variation on the response to shade or warmth. Lightgrown seedlings of $A$. thaliana were exposed to simulated deep shade or to warm temperature $\left(28^{\circ} \mathrm{C}\right)$, and compared to the control under simulated sunlight at $20^{\circ} \mathrm{C}$. Different control seedlings were used for shade and for warm temperature to ensure independent estimates of the effects of each environmental variable. We observed a strong positive correlation between the response to shade and the response to warm temperature across different accessions (Fig. 3). We evaluated the possibility that the correlation might be the spurious consequence of different growth capacities; i.e., if basal growth rate is faster the impact of environmental stimuli might be stronger, independently of the nature of the stimulus. However, this was not the case because there was no correlation between basal growth and response (Fig. S4). The hypocotyl growth responses to shade and warm temperatures are therefore genetically linked.

Convergence and divergence in transcriptome responses to shade and warmth 
We compared the transcriptome of seedlings grown in the light at $20^{\circ} \mathrm{C}$ and then either transferred to shade at $20^{\circ} \mathrm{C}$, to light at $28^{\circ} \mathrm{C}$ or to shade at $28^{\circ} \mathrm{C}$ at the beginning of the photoperiod, or left as controls in the light at $20^{\circ} \mathrm{C}$. The seedlings were harvested $10 \mathrm{~h}$ later for RNAseq. Approximately half of the differentially expressed genes $(q<0.05)$ showed effects of shade and warmth in the same direction (either promotion or inhibition), whereas the other half responded either only to shade, only to warmth or to both treatments but in opposite direction (Table S2, Fig. 4). We searched for the overrepresented GO terms within each gene cluster (Table S3). The terms at the top of each list were "developmental growth" among the genes with expression promoted by shade and warmth, "photosynthesis" among the genes with expression reduced by shade and warmth, "response to hormone stimulus" among the genes with expression enhanced only by shade, "cellular carbohydrate metabolic processes" among the genes with expression reduced only by shade, "response to heat" among both the genes with expression enhanced by warmth and reduced by shade and the genes with expression enhanced only by warmth and "response to stimulus" among the genes with expression reduced only by warmth (Fig. 4). The occurrence of genes involved in the heat stress response in plants exposed to warmth is consistent with a previous report (Cortijo et al., 2017).

Noteworthy, the GO terms "response to light stimulus" and "response to temperature stimulus" were overrepresented among the genes with expression decreased by both shade and warmth (37 and 28 genes, respectively) or by warmth alone (13 and 15 genes, respectively, Table S3). Meanwhile, none of these terms was overrepresented among the genes repressed by shade alone. Since there is relatively little overlap between the lists of genes within these two GO terms (3 genes in the cluster referred first and 5 in the second), these results highlight the transcriptional overlap by showing that many genes known to respond to one cue in addition, or actually exclusively, responded to the other.

The GO terms "response to hormone stimulus", "response to auxin stimulus", "response to brassinosteroid stimulus", "regulation of hormone levels", "auxin transport" and auxin polar transport" were overrepresented among the genes with expression enhanced by shade and warmth (Table S3). "Response to hormone stimulus" (as noted above), "response to auxin stimulus" and "response to brassinosteroid stimulus" were also overrepresented in the cluster of genes with expression enhanced only by shade (Table S3). One of the genes with expression enhanced by shade but not by warmth was IAA19 (Fig. S5); although IAA19 expression is also enhanced by warmth at a different time point (Bellstaedt et al., 2019). Conversely, the GO term "defence response" was overrepresented among the genes with expression reduced by shade and warmth as well as among 
the genes with expression reduced by warmth (Table S2), Therefore, $10 \mathrm{~h}$ after the beginning of treatments, shade affected auxin and brassinosteroid genes more extensively than warmth; whilst warmth affected defence genes more extensively than shade.

Regarding metabolic processes, the term "photosynthesis" was overrepresented among the genes with expression reduced by shade and warmth (19 genes, $p=2 e-07$ ) and those reduced only by warmth (13 genes, $p=1 e-09)$. These genes include those involved in the Calvin-Benson-Bassham cycle ( 8 genes, $p=0.007$ and 7 genes, $p=1 e-05$, respectively). Sucrose biosynthesis genes showed the same pattern ( 7 genes, $p=0.04$ and 6 genes, $p=0.00045)$. Genes involved in the biosynthesis of carotenoid, chlorophyll and flavonoids were also overrepresented $(p<0.05)$ among those with expression reduced by shade and warmth.

To get insight into the transcriptional network that controls gene expression in response to shade and/or warmth we calculated the relative enrichment of transcription factor binding target genes for each cluster of gene expression. Then we used hierarchical clustering to investigate the similarity in enrichment of transcription factor binding genes among the groups of gene expression shown in Figure 4. All the groups showing promotion of expression by shade grouped together, diverging from those showing inhibition of expression by shade at the most distant branching point (Fig. 5, S6). Conversely, the gene groups showing enhanced expression in response to warmth did not group together, diverging at the most distant branching point. This means that based on the signature of transcription factors potentially binding their promoters, the genes with expression enhanced by temperature split into a group closer to those promoted by shade and another group closer to those repressed by shade (Fig. 5). The putative binding target genes of PIF1, PIF3, PIF4, PIF5 and PIF7 are overrepresented (Tian et al., 2020) among the genes with expression enhanced by shade and warmth but not among the genes enhanced by warmth and repressed or unaffected by shade (Table S4b). Conversely, HEAT STRESS TRANSCRIPTION FACTOR A-4a (HSFA4A), HSFA1E, HSFA6A, HSFA6B, HSFB2A, HSFA1B/HSF3, HSFB3, HSFB4 and HSFC1 have the opposite pattern (Fig. S7, Table S4b). The latter is consistent with the established role of PIFs in shade avoidance and thermomorphogenesis (Fig. 1) and that of HSFs in responses to heat stress (Ohama et al., 2017).

\section{Warm temperature enhances phototropism}

In light-grown seedlings, the low red / far-red ratios and low blue-light levels of shade promote the extent of phototropic response (Goyal et al., 2016; Boccaccini et al., 2020). Unexpectedly, "tropism" 
appeared overrepresented among the genes with expression enhanced by shade and warm temperature (Table S2, Fig. 6a). Shade enhances seedling phototropism by increasing auxin levels in the hypocotyl and we observed elevated auxin signalling status (revealed by reduced DII-VENUS fluorescence) both under shade and warmth Fig. 6b) suggesting that phototropism might also be enhanced by warm temperatures. We therefore tested this hypothesis independently by growing the seedlings under white light at $20^{\circ} \mathrm{C}$ and transferring them to unilateral white light at three different temperatures at the beginning of the photoperiod of the fourth day (i.e., the same time protocol as in shade experiments but using unilateral light instead of light or shade from above). The degree of bending, measured $10 \mathrm{~h}$ later, increased with temperature (Fig. 6c). This response to warmth is significant because phototropism enhances tissue radiation load and therefore does not increase cooling.

\section{Shade, but not warmth, enhances the expression of repressors of shade avoidance.}

The GO term "response to light stimulus", including several repressors of shade avoidance such as HFR1 (Sessa et al., 2005; Hornitschek et al., 2009), PHYTOCHROME INTERACTING FACTOR 3LIKE 1 (PIL1), PHYTOCHROME RAPIDLY REGULATED 1 (PAR1) and PAR2 (Roig-Villanova et al., 2006, 2007), was overrepresented among the genes with expression enhanced by shade, but not by warmth (Fig. 7a, Table S3). Neighbour cues increase the expression of HFR1 (Sessa et al., 2005) virtually under any tested condition (Sellaro et al., 2017). Warm temperatures can also increase HFR1 expression but in seedlings exposed to red-light photoperiods (Foreman et al., 2011). Seedlings bearing the pHFR1:LUC transgene confirmed that shade but not warmth increased the activity of pHFR1 (Fig. 7b). Actually, shade had effects only at $20^{\circ} \mathrm{C}$ but not at $14^{\circ} \mathrm{C}$ or $28^{\circ} \mathrm{C}$. However, seedlings bearing the p35S:HFR1-LUC transgene, confirmed that shade reduces HFR1 protein stability (Pacín et al., 2016) and warm temperatures have the opposite effect (Foreman et al., 2011) (Fig. 7c). The impact of the hfr1 mutation on hypocotyl growth was similar irrespectively of whether growth increased in response to shade or warmth (Fig. 7d). Taken together, these observations indicate that despite very different mechanisms of response to these two environmental cues, HFR1 similarly represses the responses to shade and to warmth.

\section{Warm temperature compromises carbon balance}


As noted above, the GO term "photosynthesis" was overrepresented among the genes with expression reduced by shade and warmth. The latter include genes within the terms "photosynthesis, light harvesting", "photosynthetic electron transport chain" and "regulation of photosynthesis" (Table S2). The term "photosynthetic electron transport chain" was also overrepresented among the genes with expression reduced only by warmth (Fig. 8a). These observations prompted us to investigate the impact of warm temperature on the rate of net $\mathrm{CO}_{2}$ exchange in seedlings grown at $20^{\circ} \mathrm{C}$ and either left as controls or transferred to $28^{\circ} \mathrm{C}$ for $1 \mathrm{~h}$. Figure $8 \mathrm{~b}$ shows that increased temperature reduced net $\mathrm{CO}_{2}$ exchange and enhanced mitochondrial respiration (night exchange) of entire seedlings at the hypocotyl stage, measured inside a custom-built chamber. For a more detailed analysis, we used rosette leaves in combination with the LI-COR 6400-40 leaf chamber. Warm temperature increased the rate of respiration of the leaves measured either at the beginning or at the end of the night (Fig. 8c). The response curve of net $\mathrm{CO}_{2}$ exchange to photosynthetically active radiation revealed that warm temperature not only increased leaf respiration (net $\mathrm{CO}_{2}$ exchange at 0 $\mu \mathrm{mol} . \mathrm{m}^{-2} . \mathrm{s}^{-1}$ ) but also lowered the maximum net $\mathrm{CO}_{2}$ exchange rates obtained at high irradiances (Fig. 8d). At $28^{\circ} \mathrm{C}$ the leaves reached this plateau at lower irradiances than at $20^{\circ} \mathrm{C}$. We used these data to calculate the irradiance required to achieve the daily compensation point of a leaf, i.e., the photosynthetically active radiation required to balance during the $10 \mathrm{~h}$ of the photoperiod the $\mathrm{CO}_{2}$ released by the leaf during the night (integral of the data in Fig. $8 \mathrm{c}$ ). Since net $\mathrm{CO}_{2}$ exchange of plants exposed to $28^{\circ} \mathrm{C}$ is more negative during the night and less positive during the day, the leaves of these plants require higher irradiance than those exposed to $20^{\circ} \mathrm{C}$ to obtain a daily net $\mathrm{CO}_{2}$ exchange $=0$ (Fig. 8d, inset). This calculation is approximate because photosynthesis rates change during the day but warm temperature also decreased net $\mathrm{CO}_{2}$ exchange rates during the afternoon (Fig. 8e), indicating that diurnal fluctuations would not modify the conclusion of this analysis.

\section{Thermomorphogenesis may occur under conditions where a heat shock is unlikely}

If the function of growth responses to temperature is to reduce the risk of heat, these responses should occur when exposure to heat is likely. To investigate the shape of the response to temperature and the impact of light conditions on this response, we transferred the seedlings to different combinations of air temperature and light conditions ranging from simulated deep shade to simulated sunlight at two different irradiances. Light or shade conditions did not affect the range of response to temperature. However, the response to temperature was steeper for the plants exposed 
to shade and shallower for the plants exposed to the high-irradiance simulated sunlight (Fig. 9a). We calculated the activity of the photo-sensory receptors under the different light or shade conditions (Romero-Montepaone et al., 2020). The slope of the linear response to temperature decreased with photo-sensory receptor activity (Fig. 9b). Figure 9c shows that in terrestrial environments, the frequency of occurrence of a daily maximum temperature $\geq 35^{\circ} \mathrm{C}$, which can be considered a stressful scenario for Arabidopsis (Lippmann et al., 2019), increases sharply when the average temperature of the previous $3 \mathrm{~d}$ is between $20^{\circ} \mathrm{C}$ and $30^{\circ} \mathrm{C}$, whilst below $20^{\circ} \mathrm{C}$ heat is extremely unlikely. However, the growth rate of the hypocotyl increases linearly between $10^{\circ} \mathrm{C}$ and $30^{\circ} \mathrm{C}(\mathrm{Fig}$. $9 a)$. This indicates that thermomorphogenesis may occur within a range where a heat wave is not likely to take place. We did a meta-analysis of published RNA sequencing data using different temperatures to investigate the range of response of the different clusters with expression promoted by warmth (Fig. 4). Figure 9d shows that the genes with expression promoted by shade and warmth, where the GO term "developmental growth" is over-represented, increased their expression between $4^{\circ} \mathrm{C}$ and $30^{\circ} \mathrm{C}$. This correlates with the hypocotyl growth response to temperature. Conversely, the genes with expression promoted by warmth but not by shade, where the GO term "heat response" is over-represented (Fig. 4), enhanced their expression only at higher temperatures, correlating with the risk of heat stress (Fig. 9d).

\section{Discussion}

The similarities between growth responses to neighbour and warm-temperature cues has long been recognised, but only recently, these similarities have been extended to major components of the sensory networks. The experiments reported here, involving side-by-side light and temperature treatments expand the scope of this convergence. First, the quantitative analysis of the impact of genetic variability, due either to mutations in key components of the network (Fig. 1) or to natural variation among $A$. thaliana accessions (Fig. 3), revealed a strong genetic linkage between both responses. Second, the elevation of PIF4 protein stability by neighbour cues (Hornitschek et al., 2012) and PIF4 mRNA levels by warm temperatures (Koini et al., 2009) have been regarded as limiting factors in the growth response to these cues. Here we show that the growth system has similar quantitative sensitivity to PIF4 levels irrespectively of their enhancement by one cue or the other (Fig. 2c). The increased abundance of HDA9 in the warmth might contribute to this pattern by preventing acetylation and reduced PIF4 binding at the YUC8 promoter (Van Der Woude et al., 
2019). Third, about half of the genes that responded by shade and/or warmth responded to both in the same direction (Fig. 4). This convergence involves genes that respond to hormones like auxin and brassinosteroids, both of known importance in shade avoidance (Luccioni et al., 2002; Tao et al., 2008) and thermomorphogenesis (Gray et al., 1998; Ibañez et al., 2018) and genes related to growth among those promoted by both cues. Genes involved in photosynthesis or defence (Ballaré, 2014; Gangappa et al., 2017) are among those repressed by both cues (Fig. 4, Table S3).

At each one of the levels of analysis presented above, we observed the limits of the convergence. First, whilst most mutations had similar effects on the responses to both cues, elf3 had a much stronger impact on the response to shade than on the response to warmth (Fig. 1). This difference could be accounted for by the fact that warm temperatures reduce the binding of the evening complex to their target promoters, including PIF4 and PIF5, by a direct effect of temperature on the structure of the complex (Ezer et al., 2017; Silva et al., 2020). The effect of the elf3 mutation on the response to warmth would be reduced because under this condition ELF3 activity is already low in the wild type (Jung et al., 2020). Second, whilst the hfr1 mutation had a similar impact on the responses to shade and warmth these cues had different and even opposite effects on HFR1 transcription and HFR1 protein stability (Fig. 7). The dynamics of HFR1 could be tailored to the specific patterns of shade or warmth cues, which often differ on timing, but then the effect converges. Third, approximately half of the genes showing differential expression responded only to shade or warmth or even to both cues in opposite directions (Fig. 4).

Thermomorphogenesis helps to place sensitive organs away from the hot surface of the soil (Gray et al., 1998) and improves cooling capacity (Crawford et al., 2012; Bridge et al., 2013). A logical deduction of those observations is that the main function of thermomorphogenesis would be to avoid damaging heat events. However, some of the results reported here argue against the latter conclusion (but not against the demonstrated effects on tissue temperature). First, thermomorphogenesis occurs even under conditions where heat damage is unlikely. In fact, a survey of the probability of exposure to heat indicates that the event is unlikely if the average temperature of the previous days is below $25^{\circ} \mathrm{C}$ (Fig. 9c) whilst the hypocotyl growth response to temperature is linear in the $12-30^{\circ} \mathrm{C}$ range (Fig. 9a). In addition, shade reduces plant temperature (Legris et al., 2017) and therefore the likeness of heat damage, but the growth response to temperature is steeper under simulated shade than under simulated sunlight conditions (Fig. 9a-b). Second, since the occurrence of heat and shade do not show positive correlation in nature, specific, rather than shared signalling components would be necessary to adapt or acclimate to one risk without affecting the 
response to the other. Yet, hypocotyl growth responses to shade and warmth show strong genetic linkage (Fig. 1, 2) and share cell-growth associated genes (Fig. 4). Such strong overlap is difficult to reconcile with a scenario where shade avoidance and thermomorphogenesis have two completely different ecological purposes, such as reducing the occurrence and/or severity of shade and heat damage, respectively. Third, some of the growth responses to warmth would increase, rather than decrease temperature. Enhanced phototropism by warm temperatures (Fig. 6c) would increase the radiation load and tissue temperature, indicating that growth responses to warmth do not necessarily reduce the risk of heat.

Whilst the genes involved in thermomorphogenesis strongly overlap with those involved in shade avoidance (see above), genes involved in thermotolerance, such as HEAT SHOCK PROTEINs increased their expression in response to warmth but not in response to shade, which in fact reduced the expression of some of them (Fig. 4). The latter is consistent with the fact that shade actually reduces the probability of extreme high temperatures (Legris et al., 2017). In contrast to growth and growth-related gene expression, thermotolerance genes showed a range of response to temperature that matches the risk of heat stress (Fig. 9d). The specific control of growth responses to warmth (shared with shade) and tolerance responses to heat would involve the use of different transcription factors (Fig. 5) (Ohama et al., 2017).

The analysis of carbon balance provided insight into other negative consequences of warm conditions that do not require reaching heat. Shifting to $28^{\circ} \mathrm{C}$ a plant previously grown at $20^{\circ} \mathrm{C}$ rapidly lowered the rate of net $\mathrm{CO}_{2}$ exchange over a wide range of values of photosynthetically active radiation (Fig. 8). This likely resulted from a combination of enhanced mitochondrial respiration and photo-respiration and reduced photosynthesis caused by warm temperatures (Dusenge et al., 2019). Consequently, at $28^{\circ} \mathrm{C} A$. thaliana leaves required substantially more photosynthetically active radiation than at $20^{\circ} \mathrm{C}$ to reach the daily compensation point (i.e. a null net $\mathrm{CO}_{2}$ exchange during the 24 h cycle, Fig. 8d, inset).

We therefore propose that the major function of growth responses to warm temperature is to enhance shade avoidance, rather than reducing the risk of heat damage. Shared signalling supports shared ecological functions between growth responses to shade and warmth. Shade avoidance is indeed stronger under warm temperatures (Romero-Montepaone et al., 2020). Furthermore, not only shade (Goyal et al., 2016; Boccaccini et al., 2020) but also warm temperatures (Fig. 6c) increase hypocotyl phototropism which helps foraging for light. According to the proposed interpretation, the evolutionary force behind enhanced stem and petiole growth, leaf hyponasty and phototropism under 
warm environments would be to place the foliage at better light positions because at warm temperatures plants need more light to compensate their carbon balance. In fact, the rates of respiration (Armstrong et al., 2006), the rate of growth (Fig. 9a) and the expression of growth-related genes (Fig. 9d) increase over a comparable temperature range. In this context, the increased cooling capacity gained during thermomorphogenesis (Crawford et al., 2012; Bridge et al., 2013) would help to reduce respiration, complementing the enhanced ability to capture light.

\section{Acknowledgements}

We thank Salomé Prat (Department of Plant Molecular Genetics, Centro Nacional de Biotecnología, Consejo Superior de Investigaciones Científicas, Madrid) for her kind provision of pPIF4:PIF4-LUC. This work was supported by grants from the University of Buenos Aires (grant no. 20020170100505BA) and Agencia Nacional de Promoción Cientıfica yTecnologica (grant nos. PICT2016-1459 and PICT-2018-01695).

\section{Author contributions}

S.R.-M., R.S., E.P., M.J.Y. and J.J.C. planned and designed the research, S.R.-M., R.S., C.E.H., C.C.-R. and E.P. performed experiments, S.R.-M., R.S., C.S.H., L.B., E.P. and J.J.C. analysed data and J.J.C. wrote the manuscript with input from the other authors.

\section{References}

Armstrong AF, Logan DC, Atkin OK. 2006. On the developmental dependence of leaf respiration: Responses to short- and long-term changes in growth temperature. American Journal of Botany $\mathbf{9 3}$ : 1633-1639.

Ballaré CL. 2014. Light regulation of plant defense. Annual Review of Plant Biology 65: 335-63.

Ballaré CL, Pierik R. 2017. The shade-avoidance syndrome: Multiple signals and ecological consequences. Plant Cell and Environment 11: 2530-2543.

Bellstaedt J, Trenner J, Lippmann R, Poeschl Y, Zhang X, Friml J, Quint M, Delker C. 2019. A mobile auxin signal connects temperature sensing in cotyledons with growth responses in hypocotyls. Plant physiology 180: 757-766.

Blanco-Touriñán N, Legris M, Minguet EG, Costigliolo-Rojas C, Nohales MA, Iniesto E, GarcíaLeón M, Pacín M, Heucken N, Blomeier T, et al. 2020. COP1 destabilizes DELLA proteins in 
Arabidopsis. Proceedings of the National Academy of Sciences of the United States of America 117: 13792-13799.

Boccaccini A, Legris M, Krahmer J, Allenbach Petrolati L, Goyal A, Ampudia CG, Vernoux T, Karayekov E, Casal JJ, Fankhauser C. 2020. Low blue light enhances phototropism by releasing cryptochrome 1-mediated inhibition of PIF4 expression. Plant Physiology 183: 1780-1793.

Bridge LJ, Franklin KA, Homer ME. 2013. Impact of plant shoot architecture on leaf cooling: a coupled heat and mass transfer model. Journal of the Royal Society, Interface / the Royal Society 10: 20130326.

Casal JJ. 2013. Photoreceptor signaling networks in plant responses to shade. Annual Review of Plant Biology 64: 403-427.

Casal JJ, Balasubramanian S. 2019. Thermomorphogenesis. Annual Review of Plant Biology 70 : 321-346.

Chow CN, Lee TY, Hung YC, Li GZ, Tseng KC, Liu YH, Kuo PL, Zheng HQ, Chang WC. 2019.

Plantpan3.0: A new and updated resource for reconstructing transcriptional regulatory networks from chip-seq experiments in plants. Nucleic Acids Research 47: D1155-D1163.

Chung BYW, Balcerowicz M, Di Antonio M, Jaeger KE, Geng F, Franaszek K, Marriott P, Brierley I, Firth AE, Wigge PA. 2020. An RNA thermoswitch regulates daytime growth in Arabidopsis. Nature Plants 6: 522-532.

Cortijo S, Charoensawan V, Brestovitsky A, Buning R, Ravarani C, Rhodes D, van Noort J, Jaeger KE, Wigge PA. 2017. Transcriptional regulation of the ambient temperature response by H2A.Z nucleosomes and HSF1 transcription factors in Arabidopsis. Molecular Plant 10: 1258-1273. Crawford AJ, McLachlan DH, Hetherington AM, Franklin KA. 2012. High temperature exposure increases plant cooling capacity. Current biology 22: R396-7.

Delker C, Sonntag L, James G, Janitza P, Ibañez C, Ziermann H, Peterson T, Denk K, Mull S, Ziegler J, et al. 2014. The DET1-COP1-HY5 pathway constitutes a multipurpose signaling module regulating plant photomorphogenesis and thermomorphogenesis. Cell Reports 9: 1983-1989.

Duek PD, Elmer M V, Van Oosten VR, Fankhauser C. 2004. The degradation of HFR1, a putative bHLH class transcription factor involved in light signaling, is regulated by phosphorylation and requires COP1. Current Biology 14: 2296-2301.

Dusenge ME, Duarte AG, Way DA. 2019. Plant carbon metabolism and climate change: elevated $\mathrm{CO}_{2}$ and temperature impacts on photosynthesis, photorespiration and respiration. New Phytologist 221: $32-49$. 
Ezer D, Jung J-H, Lan H, Biswas S, Gregoire L, Box MS, Charoensawan V, Cortijo S, Lai X, Stöckle D, et al. 2017. The evening complex coordinates environmental and endogenous signals in Arabidopsis. Nature Plants 3: 17087.

Falconer DS, Mackay TFC. 1996. Introduction to quantitative genetics. Harlow, Essex, UK: Longmans Green.

Fiorucci A-S, Galvão VC, Ince YÇ, Boccaccini A, Goyal A, Allenbach Petrolati L, Trevisan M, Fankhauser C. 2020. PHYTOCHROME INTERACTING FACTOR 7 is important for early responses to elevated temperature in Arabidopsis seedlings. New Phytologist 226: 50-58.

Foreman J, Johansson H, Hornitschek P, Josse E-MM, Fankhauser C, Halliday KJ. 2011. Light receptor action is critical for maintaining plant biomass at warm ambient temperatures. Plant Journal 65: 441-452.

Franklin KA, Lee SH, Patel D, Kumar SV, Spartz AK, Gu C, Ye S, Yu P, Breen G, Cohen JD, et al. 2011. PHYTOCHROME-INTERACTING FACTOR 4 (PIF4) regulates auxin biosynthesis at high temperature. Proceedings of the National Academy of Sciences, USA 108: 20231-20235.

Gangappa SN, Berriri S, Kumar SV. 2017. PIF4 coordinates thermosensory growth and immunity in Arabidopsis. Current Biology 27: 243-249.

Goyal A, Karayekov E, Galvão VC, Ren H, Casal JJ, Fankhauser C. 2016. Shade promotes phototropism through phytochrome B-controlled auxin production. Current Biology 26: 3280-3287.

Gray WM, Östin A, Sandberg G, Romano CP, Estelle M. 1998. High temperature promotes auxinmediated hypocotyl elongation in Arabidopsis. Proceedings of the National Academy of Sciences of the United States of America 95: 7197-7202.

Grinevich DO, Desai JS, Stroup KP, Duan J, Slabaugh E, Doherty CJ. 2019. Novel transcriptional responses to heat revealed by turning up the heat at night. Plant Molecular Biology 101: 1-19.

Hornitschek P, Kohnen M V, Lorrain S, Rougemont J, Ljung K, López-Vidriero I, FrancoZorrilla JM, Solano R, Trevisan M, Pradervand S, et al. 2012. Phytochrome interacting factors 4 and 5 control seedling growth in changing light conditions by directly controlling auxin signaling. Plant Journal 71: 699-711.

Hornitschek P, Lorrain S, Zoete V, Michielin O, Fankhauser C. 2009. Inhibition of the shade avoidance response by formation of non-DNA binding bHLH heterodimers. EMBO Journal 28: 38933902.

Huang X, Zhang Q, Jiang Y, Yang C, Wang Q, Li L. 2018. Shade-induced nuclear localization of 
PIF7 is regulated by phosphorylation and 14-3-3 proteins in Arabidopsis. eLife 7: e31636.

Ibañez C, Delker C, Martinez C, Bürstenbinder K, Janitza P, Lippmann R, Ludwig W, Sun H, James GV, Klecker M, et al. 2018. Brassinosteroids dominate hormonal regulation of plant thermomorphogenesis via BZR1. Current Biology 28: 303-310.

Johansson H, Jones HJ, Foreman J, Hemsted JR, Stewart K, Grima R, Halliday KJ. 2014. Arabidopsis cell expansion is controlled by a photothermal switch. Nature Communications 5: 4848. Jung JH, Barbosa AD, Hutin S, Kumita JR, Gao M, Derwort D, Silva CS, Lai X, Pierre E, Geng F, et al. 2020. A prion-like domain in ELF3 functions as a thermosensor in Arabidopsis. Nature 585: 256-260.

Jung J-H, Domijan M, Klose C, Biswas S, Ezer D, Gao M, Box MS, Charoensawan V, Cortijo S, Locke JC, et al. 2016. Phytochromes function as thermosensors in Arabidopsis. Science 354: 886889.

Katari MS, Nowicki SD, Aceituno FF, Nero D, Kelfer J, Thompson LP, Cabello JM, Davidson RS, Goldberg AP, Shasha DE, et al. 2010. VirtualPlant: a software platform to support systems biology research. Plant physiology 152: 500-15.

Keller MM, Jaillais Y, Pedmale U V, Moreno JE, Chory J, Ballare CL. 2011. Cryptochrome 1 and phytochrome $\mathrm{B}$ control shade-avoidance responses in Arabidopsis via partially independent hormonal cascades. Plant Journal 67: 195-207.

Koini MA, Alvey L, Allen T, Tilley C a, Harberd NP, Whitelam GC, Franklin KA. 2009. High temperature-mediated adaptations in plant architecture require the bHLH transcription factor PIF4. Current Biology 19: 408-13.

Lamesch P, Berardini TZ, Li D, Swarbreck D, Wilks C, Sasidharan R, Muller R, Dreher K, Alexander DL, Garcia-Hernandez M, et al. 2012. The Arabidopsis Information Resource (TAIR): improved gene annotation and new tools. Nucleic acids research 40: D1202-10.

Lau OS, Deng XW. 2012. The photomorphogenic repressors COP1 and DET1: 20 years later. Trends in Plant Science 17: 584-593.

Lau K, Podolec R, Chappuis R, Ulm R, Hothorn M. 2019. Plant photoreceptors and their signaling components compete for COP1 binding via VP peptide motifs. The EMBO Journal 38: e102140.

Law C, Chen Y, Shi W, Smyth G. 2014. voom: Precision weights unlock linear model analysis tools for RNA-seq read counts. Genome Biology 15: R29.

Legris M, Klose C, Burgie E., Costigliolo Rojas C, Neme M, Hiltbrunner A, Wigge PA, Schäfer E, Vierstra RD, Casal JJ. 2016. Phytochrome B integrates light and temperature signals in 
Arabidopsis. Science 354: 897-900.

Legris M, Nieto C, Sellaro R, Prat S, Casal JJ. 2017. Perception and signalling of light and temperature cues in plants. The Plant Journal 90: 683-697.

Li L, Ljung K, Breton G, Schmitz RJ, Pruneda-Paz J, Cowing-Zitron C, Cole BJ, Ivans LJ, Pedmale U V, Jung H-SH-S, et al. 2012. Linking photoreceptor excitation to changes in plant architecture. Genes and Development 26: 785-790.

Lippmann R, Babben S, Menger A, Delker C, Quint M. 2019. Development of wild and cultivated plants under global warming conditions. Current Biology 29: R1326-R1338.

Lorrain S, Allen T, Duek PD, Whitelam GC, Fankhauser C. 2008. Phytochrome-mediated inhibition of shade avoidance involves degradation of growth-promoting bHLH transcription factors. Plant Journal 53: 312-323.

Luccioni LG, Oliverio KA, Yanovsky MJ, Boccalandro H, Casal JJ. 2002. Brassinosteroid mutants uncover fine tunning of phytochrome signaling. Plant Physiology 178: 173-181.

Ma D, Li X, Guo Y, Chu J, Fang S, Yan C, Noel JP, Liu H. 2016. Cryptochrome 1 interacts with PIF4 to regulate high temperature-mediated hypocotyl elongation in response to blue light.

Proceedings of the National Academy of Sciences of the United States of America 113: 224-9. Mueller AL, Zhang P, Rhee SY. 2003. AraCyc: A biochemical pathway database for Arabidopsis. Plant Physiology 132: 453-460.

Nusinow D a, Helfer A, Hamilton EE, King JJ, Imaizumi T, Schultz TF, Farré EM, Kay S a. 2011. The ELF4-ELF3-LUX complex links the circadian clock to diurnal control of hypocotyl growth. Nature 475: 398-402.

Ohama N, Sato H, Shinozaki K, Yamaguchi-Shinozaki K. 2017. Transcriptional regulatory network of plant heat stress response. Trends in Plant Science 22: 53-65.

Osterlund MT, Hardtke NW, Deng XW. 2000. Targeted destabilization of HY5 during light-regulated development of Arabidopsis. Nature 405: 462-466.

Pacín M, Legris M, Casal JJ. 2013. COP1 re-accumulates in the nucleus under shade. Plant Journal 75: 631-641.

Pacín M, Semmoloni M, Legris M, Finlayson SA, Casal JJ. 2016. Convergence of CONSTITUTIVE PHOTOMORPHOGENESIS 1 and PHYTOCHROME INTERACTING FACTOR signalling during shade avoidance. New Phytologist 211: 967-979.

Park Y-J, Lee H-J, Ha J-H, Kim JY, Park C-M. 2017. COP1 conveys warm temperature information to hypocotyl thermomorphogenesis. New Phytologist 215: 269-280. 
Pedmale U V, Celaya RB, Liscum E. 2010. Phototropism: mechanism and outcomes. The Arabidopsis Book 8: e0125.

Poorter H, Niinemets Ü, Ntagkas N, Siebenkäs A, Mäenpää M, Matsubara S, Pons T. 2019. A meta-analysis of plant responses to light intensity for 70 traits ranging from molecules to whole plant performance. New Phytologist 223: 1073-1105.

Procko C, Crenshaw CM, Ljung K, Noel JP, Chory J. 2014. Cotyledon-generated auxin is required for shade-induced hypocotyl growth in Brassica rapa. Plant physiology 165: 1285-1301.

Pucciariello O, Legris M, Rojas CC, Iglesias MJ, Hernando CE, Dezar C, Vazquez M, Yanovsky MJ, Finlayson SA, Prat S, et al. 2018. Rewiring of auxin signaling under persistent shade. Proceedings of the National Academy of Sciences of the United States of America 115: 5612-5617. Quint M, Delker C, Franklin KA, Wigge PA, Halliday KJ, van Zanten M. 2016. Molecular and genetic control of plant thermomorphogenesis. Nature Plants 2: 15190.

R Core Team. 2017. R: A language and environment for statistical computing. Version:4.0.3. R Foundation for Statistical Computing, Vienna, Austria.

Roig-Villanova I, Bou-Torrent J, Galstyan A, Carretero-Paulet L, Portolés S, RodríguezConcepción M, Martínez-García JF. 2007. Interaction of shade avoidance and auxin responses: A role for two novel atypical bHLH proteins. EMBO Journal 26: 4756-4767.

Roig-Villanova I, Bou J, Sorin C, Devlin PF, Martinez-García JF. 2006. Identification of primary target genes of phytochrome signaling. Early transcriptional control during shade avoidance responses in Arabidopsis. Plant Physiology 141: 85-96.

Romero-Montepaone S, Poodts S, Fischbach P, Sellaro R, Zurbriggen MD, Casal JJ. 2020. Shade avoidance responses become more aggressive in warm environments. Plant Cell and Environment 43: 1625-1636.

Schlaen RG, Mancini E, Sanchez SE, Perez-Santángelo S, Rugnone ML, Simpson CG, Brown JWS, Zhang X, Chernomoretz A, Yanovsky MJ. 2015. The spliceosome assembly factor GEMIN2 attenuates the effects of temperature on alternative splicing and circadian rhythms. Proceedings of the National Academy of Sciences of the United States of America 112: 9382-9387.

Sellaro R, Crepy M, Trupkin SA, Karayekov E, Buchovsky AS, Rossi C, Casal JJ. 2010. Cryptochrome as a sensor of the blue/green ratio of natural radiation in Arabidopsis. Plant Physiology 154: 401-409.

Sellaro R, Pacín M, Casal JJ. 2017. Meta-analysis of the transcriptome reveals a core set of shadeavoidance genes in Arabidopsis. Photochemestry and Photobiology 93: 692-702. 
Sellaro R, Smith RW, Legris M, Fleck C, Casal JJ. 2019. Phytochrome B dynamics departs from photoequilibrium in the field. Plant, Cell \& Environment 42: 606-617.

Sessa G, Carabelli M, Sassi M, Ciolfi A, Possenti M, Mittempergher F, Becker J, Morelli G, Ruberti I. 2005. A dynamic balance between gene activation and repression regulates the shade avoidance response in Arabidopsis. Genes and Development 19: 2811-2815.

Silva CS, Nayak A, Lai X, Hutin S, Hugouvieux V, Jung J-H, López-Vidriero I, Franco-Zorrilla JM, Panigrahi KCS, Nanao MH, et al. 2020. Molecular mechanisms of Evening Complex activity in Arabidopsis. Proceedings of the National Academy of Sciences of the United States of America 117: 6901-6909.

Smith H. 2000. Phytochromes and light signal perception by plants--an emerging synthesis. Nature 407: 585-590.

Storey JD, Tibshirani R. 2003. Statistical significance of genomewide studies. Proceedings of the National Academy of Sciences, USA 100: 9440-9445.

Suzuki R, Shimodaira H. 2006. Pvclust: An R package for assessing the uncertainty in hierarchical clustering. Bioinformatics 22: 1540-1542.

Tao Y, Ferrer JL, Ljung K, Pojer F, Hong F, Long JA, Li L, Moreno JE, Bowman ME, Ivans LJ, et al. 2008. Rapid synthesis of auxin via a new tryptophan-dependent pathway is required for shade avoidance in plants. Cell 133: 164-176.

Tasset C, Singh Yadav A, Sureshkumar S, Singh R, van der Woude L, Nekrasov M, Tremethick D, van Zanten M, Balasubramanian S. 2018. POWERDRESS-mediated histone deacetylation is essential for thermomorphogenesis in Arabidopsis thaliana. PLoS Genetics 14: 1-21.

Tian F, Yang DC, Meng YQ, Jin J, Gao G. 2020. PlantRegMap: Charting functional regulatory maps in plants. Nucleic Acids Research 48: D1104-D1113.

Trapnell C, Pachter L, Salzberg SL. 2009. TopHat: discovering splice junctions with RNA-Seq. Bioinformatics 25: 1105-11.

Van Der Woude LC, Perrella G, Snoek BL, Van Hoogdalem M, Novák O, Van Verk MC, Van Kooten HN, Zorn LE, Tonckens R, Dongus JA, et al. 2019. HISTONE DEACETYLASE 9 stimulates auxin-dependent thermomorphogenesis in Arabidopsis thaliana by mediating H2A.Z depletion. Proceedings of the National Academy of Sciences of the United States of America 116: 25343-25354.

Yang R, Hong Y, Ren Z, Tang K, Zhang H, Zhu JK, Zhao C. 2019. A role for PICKLE in the regulation of cold and salt stress tolerance in arabidopsis. Frontiers in Plant Science 10: 1-11. 
Zhang SS, Yang H, Ding L, Song ZT, Ma H, Chang F, Liu JX. 2017. Tissue-specific

transcriptomics reveals an important role of the unfolded protein response in maintaining fertility upon heat stress in arabidopsis. Plant Cell 29: 1007-1023.

The following Supporting Information is available for this article:

Fig. S1. The hypocotyl-growth response observed during the first day under warmth temperatures is thermomorphogenic.

Fig. S2. Calculation of the impact of different mutants on the response to shade and to warmth.

Fig. S3. Representative confocal fluorescence images of $p$ PIF4:PIF4-GFP.

Fig. S4. The hypocotyl-growth responses to shade or warmth do not correlate with the hypocotyl growth rate under control condition.

Fig. S5. IAA19 gene expression and promoter activity.

Fig. S6. Detail of the analysis of promoter similarities.

Fig. S7. Overrepresented transcription factor binding sites among gene clusters with expression enhanced by warmth.

Table S1. Mutants, transgenic lines and accessions of Aradidopsis thaliana (Columbia background) used in this study.

Table S2. Clusters of differentially expressed genes in response to warmth and/or shade.

Table S3. GO terms overrepresented among the clusters of differentially expressed genes.

Table S4. Transcription factor binding sites among the genes of each cluster of expression. 


\section{FIGURE LEGENDS}

Fig. 1. Similar quantitative impact of several mutations on the hypocotyl growth response to shade and to warmth. Three-day-old seedlings of the wild type Columbia of Arabidopsis thaliana and of the indicated mutants were exposed during the photoperiod of day $4(10 \mathrm{~h})$ to different combinations of light/shade and temperature either under controlled conditions (circles) or in the field (squares) and the growth rate was measured during this period. (a) Growth of the indicated single or multiple mutant plotted against the growth of the Columbia wild type grown under the same conditions. Each datum point represents a light/shade and temperature combination and is mean $\pm S E$ of four biological replicates. For each mutant, the same data are represented with the symbols corresponding to the light/shade conditions (left) and to the temperature conditions (right). For field data, the temperature symbol corresponds to the closest average temperature during the $10 \mathrm{~h}$ when growth was measured. The dotted 1:1 line represents the case of no effect of the mutation (impact= 1). The points above and below this line indicate that the mutant responds more (impact $>1$ ) or less (impact <1) than the wild type, respectively. The solid line represents the relationship between the growth of the mutant and that of the wild type across all light/shade and temperature combinations. Note that for the elf3 mutant most data corresponding to deep shade are above the solid line, indicating that this mutation enhances more the response to shade than the response to warmth. (b) Impact of the different mutations on the response to shade plotted against the impact of the same mutation in the response to warmth. For elf3, the impact on the response to shade is significantly larger than the impact on the response to warmth $(P<0.01)$ in ANOVA followed by Bonferroni tests. The impacts \pm SE were calculated by multiple linear regression analysis from the data shown in (a).

Fig. 2. The abundance of PIF4 correlates with hypocotyl growth rates under shade and warmth. (a) Fluorescence driven by the pPIF4:PIF4-GFP transgene in hypocotyl epidermal and sub-epidermal cells. (b) Luminescence driven by the pPIF4:PIF4-LUC transgene. (c-d) Hypocotyl growth plotted against the PIF4 data shown in (a) and (b), respectively. Three-day-old seedlings of the wild type Columbia of Arabidopsis thaliana and of the indicated mutants were exposed during the photoperiod of day $4(10 \mathrm{~h})$ to different combinations of light/shade and temperature. Each datum point is mean $\pm S E$ of three (b) four (a, c-d) biological replicates. The significance of the correlation is indicated. 
Fig. 3. Correlation of natural variation in hypocotyl-growth responses to shade and warmth. Threeday-old seedlings of different accessions of Arabidopsis thaliana (Supporting Information Table S1) were exposed during the photoperiod of day $4\left(10 \mathrm{~h}\right.$ ) to light at $20^{\circ} \mathrm{C}$ (control), light at $28^{\circ} \mathrm{C}$ (warmth) or deep shade at $20^{\circ} \mathrm{C}$. The differences in hypocotyl growth rates between warmth and control conditions is plotted against the difference between shade and control conditions. Each datum point is mean $\pm \mathrm{SE}$ of four biological replicates. The genetic correlation between the response to warmth and the response to shade (calculated for the accession means as the ratio between the covariance between both traits and the product of the square roots of the among accession variance for each trait (Falconer \& Mackay, 1996)) is 0.69 and the significance is indicated. Two accessions (Cas-0, Ms-0) showed significantly stronger response to shade than to warmth $(P<0.05)$ in ANOVA followed by Bonferroni tests.

Fig. 4. Convergent and divergent transcriptome responses to shade and warmth. Differentially expressed genes were grouped according to the promotion $(\uparrow)$ or inhibition $(\downarrow)$ caused by deep shade and/or warmth $\left(28^{\circ} \mathrm{C}\right)$ in Arabidopsis thaliana. The parts-to-a-whole chart shows the proportion and absolute numbers of differentially expressed genes within each group. The surrounding box-plots show median, 1-3 interquartile range and maximum-minimum interval of the log-fold changes of expression of each gene of the cluster corresponding to its top overrepresented GO term (except when no significant terms are present). Each datum point represents the difference between the average Voom transformed count data corresponding to the indicated condition and the control (light, $20^{\circ} \mathrm{C}$ ). Averages are based on three biological replicates (Supporting Information Table S2). The size and colour of the circles indicate the fold enrichment and its statistical significance.

Fig. 5. Different signatures of transcription factor binding for the genes with expression enhanced by warmth and either promoted or unaffected/inhibited by shade in Arabidopsis thaliana. The enrichment of transcription factor binding target genes (Chow et al., 2019) was calculated for the gene clusters defined by expression increased $(\uparrow)$ or decreased $(\downarrow)$ by shade and/or warmth (Fig. 4). Similar signatures appear closer in the tree generated by hierarchical clustering. Bootstrap probability values (blue, above) and approximately unbiased probability values (orange, below) are indicated (Suzuki \& Shimodaira, 2006). See Supporting Information Fig. S6 for further detail of the analysis. 
Fig. 6. Warm temperatures increase phototropism in Arabidopsis thaliana. (a) The GO term "tropism" is overrepresented among the genes with expression enhanced by warmth $\left(28^{\circ} \mathrm{C}\right)$. Box-plots show median, 1-3 interquartile range and maximum-minimum interval of the log-fold changes of expression of each gene of the cluster corresponding to the indicated GO term. Each datum point represents the difference between the average Voom transformed count data corresponding to the indicated condition and the control (light, $20^{\circ} \mathrm{C}$ ). Averages are based on three biological replicates (Supporting Information Table S2). (b) Normalised fluorescence driven by DII-VENUS in the hypocotyl is reduced by deep shade as well as warmth $\left(28^{\circ} \mathrm{C}\right)$. Reduced DII-VENUS fluorescence indicates stronger auxin signalling. Data are means \pm SE of four biological replicates (c) Hypocotyl curvature in response to unilateral blue light provided at the indicated temperature. Data are means $\pm S E$ of four biological replicates. The significance of the regression is indicated.

Fig. 7. HFR1 similarly affects hypocotyl growth responses to shade and warmth despite different transcriptional and post-transcriptional responses to these cues in Arabidopsis thaliana. (a) The GO term "shade avoidance" is overrepresented among the genes with expression enhanced by shade. Box-plots show median, 1-3 interquartile range and maximum-minimum interval of the log-fold changes of expression of each gene of the cluster corresponding to the indicated GO term plus HFR1. Each datum point represents the difference between the average Voom transformed count data corresponding to the indicated condition and the control (light, $20^{\circ} \mathrm{C}$ ). Averages are based on three biological replicates (Supporting Information Table S2). (b) Luminescence driven by the pHFR1:LUC transgene. (c) Luminescence driven by the p35S:HFR1-LUC transgene. (d) Growth of the hfr1 mutant plotted against the growth of the Columbia wild type grown under the same conditions. Note that neither light nor temperature conditions cause departures from the solid line. Dotted line represents the case of no impact of the mutation. Each datum point is mean $\pm S E$ of three (b-c) four (d) replicate boxes.

Fig. 8. Warm temperatures compromise the carbon balance in Arabidopsis thaliana. (a) The GO term "photosynthetic electron transport chain" is overrepresented among the genes with expression reduced by warmth. Box-plots show median, 1-3 interquartile range and maximum-minimum interval of the log-fold changes of expression of each gene of the cluster corresponding to the indicated GO term. Each datum point represents the difference between the average Voom transformed count data corresponding to the indicated condition and the control (light, $20^{\circ} \mathrm{C}$ ). Averages are based on 
three biological replicates (Supporting Information Table S2). (b) Warm temperature decreases daytime carbon dioxide gains and enhances night-time respiration in entire seedlings at the hypocotyl stage. Measurements were conducted 8-10 h after the beginning of the photoperiod and 0.5-2.5 $\mathrm{h}$ after the beginning of the night (photosynthetically active radiation: 900 and $0 \mu \mathrm{mol} \mathrm{m}^{-2} \mathrm{~s}^{-1}$, respectively). Box-plots show median, 1-3 interquartile range and maximum-minimum interval of 9 replicate boxes with seedlings expressed per unit dry weight. (c) Warm temperature enhances respiration of rosette leaves measured $0.5-2.5 \mathrm{~h}$ and $12-14 \mathrm{~h}$ after the beginning of the night. Box-plots show median, 1-3 interquartile range and maximum-minimum interval of 13-15 replicates. (d) Leaf net carbon dioxide exchange rates measured 2-6 $\mathrm{h}$ after the beginning of the photoperiod plotted against photosynthetically active radiation. Data are means $\pm S E$ of nine plants. The inset shows a detail of the response curves where the horizontal lines indicate the net carbon dioxide exchange rates required during the day to compensate carbon losses during the night (from c) at each temperature (calculated for a rosette leaf). The arrows point to the photosynthetically active radiation required to achieve the daily compensation point of leaf net carbon dioxide exchange. (e) Warm temperature reduces net carbon dioxide exchange rates of rosette leaves 8-10 $\mathrm{h}$ after the beginning of the photoperiod $\left(2000 \mu \mathrm{mol} \mathrm{m} \mathrm{m}^{-2} \mathrm{~s}^{-1}\right)$. Box-plots show median, 1-3 interquartile range and maximum-minimum interval of 15 replicates. In b-c, e, significant effects of temperature are indicated.

Fig. 9. Growth responses to temperature can occur within a range where heat stress events are unlikely. (a) Growth rate of Arabidopsis thaliana under the indicated light/shade conditions plotted against temperature. (b) Slope of the response shown in (a) plotted against photoreceptor activity calculated on the basis of light/shade conditions (the sum of the terms corresponding to phyB, phytochrome A and cryptochrome activities in the model by Romero-Montepaone et al., 2020). (c) Frequency of occurrence of maximum temperatures equal or higher than $35^{\circ} \mathrm{C}$ as affected by the average temperature during the 4 previous days. (d) Meta-analysis based on publicly available RNA sequencing data of de gene clusters that showed expression enhanced by warm temperatures (see Fig. 4). The pattern of the cluster with expression enhanced by shade and warmth correlates with the growth response (from a). The pattern of the clusters with expression enhanced by warmth and either unaffected or repressed by shade correlates with the frequency of occurrence of maximum temperatures equal or higher than $35^{\circ} \mathrm{C}$ (from c). In a-b, d, error bars are SE. 


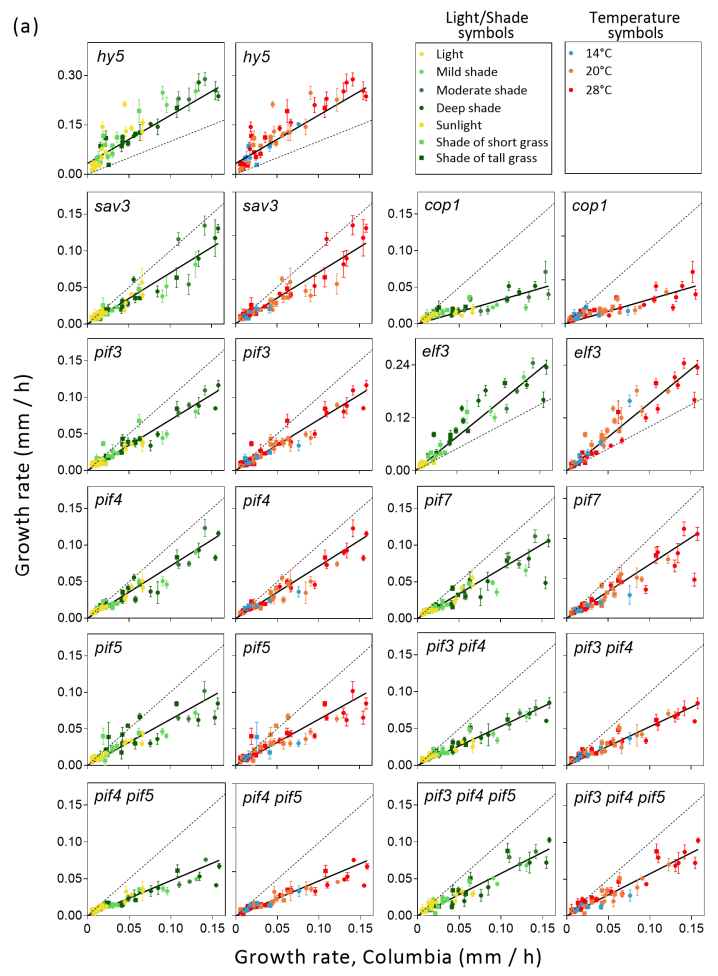

(b)

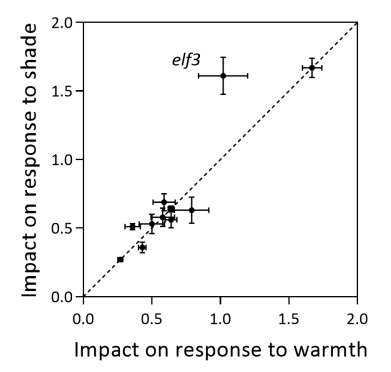

nph_17430_f1.tif 

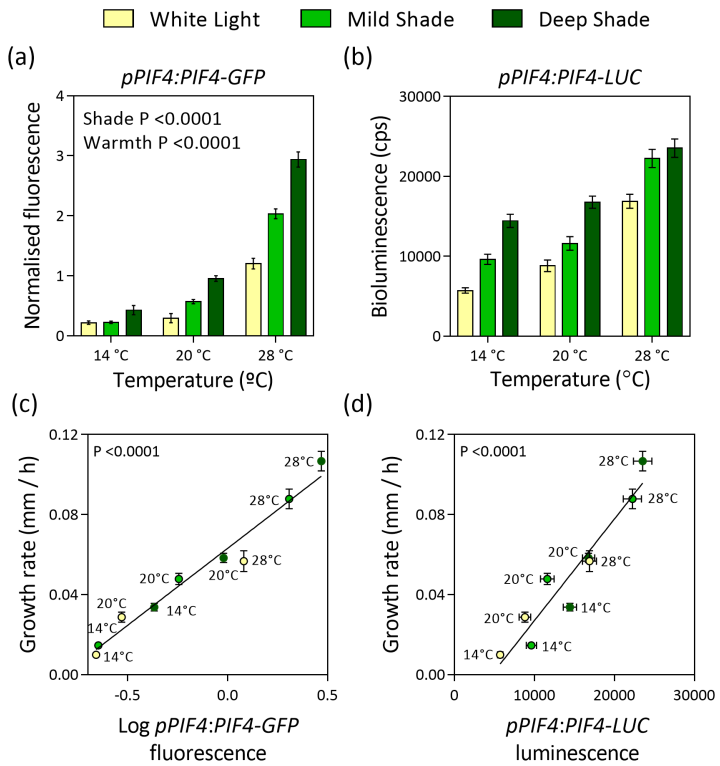

nph_17430_f2.tif 


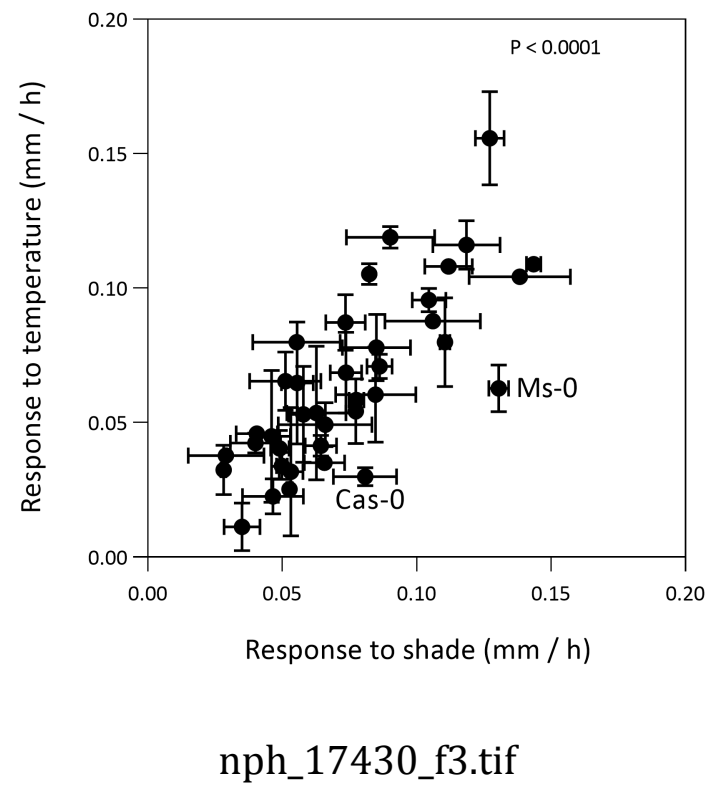

This article is protected by copyright. All rights reserved 




nph_17430_f4.tif 

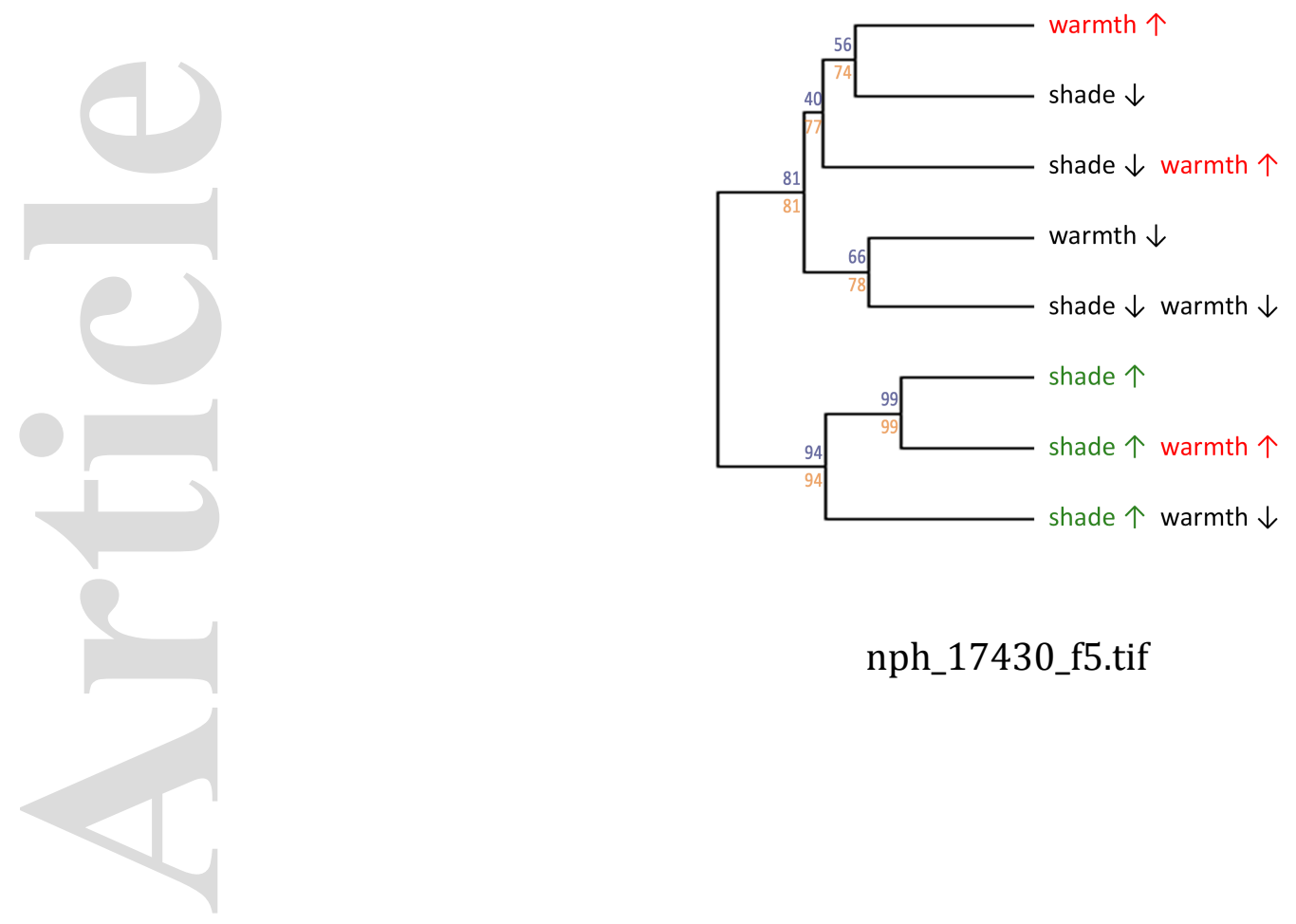

nph_17430_f5.tif 

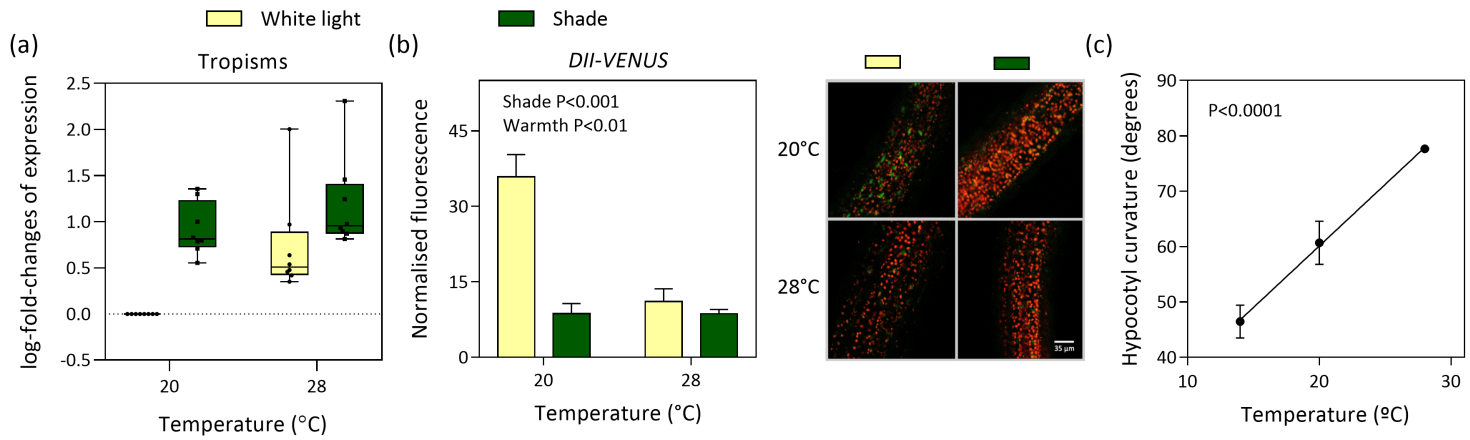

nph_17430_f6.tif 

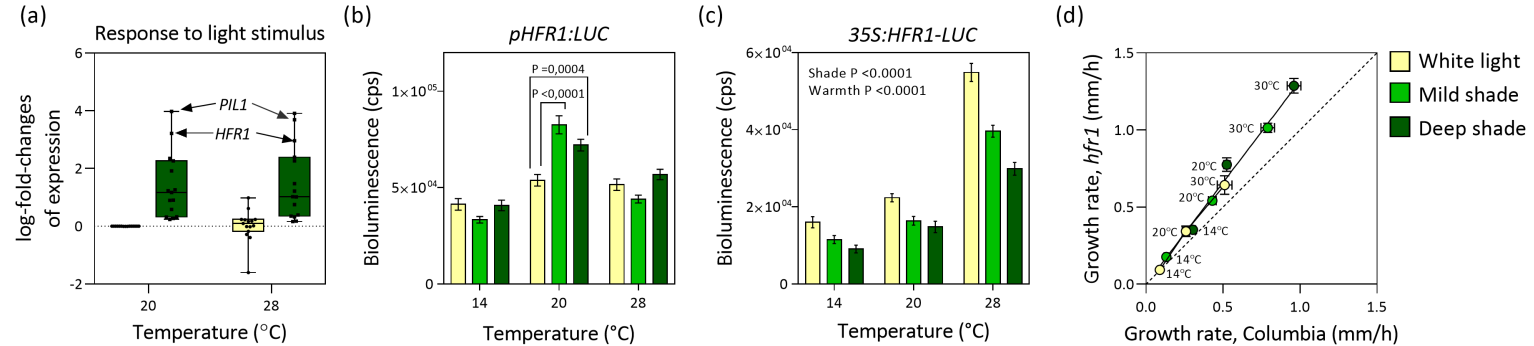

nph_17430_f7.tif 

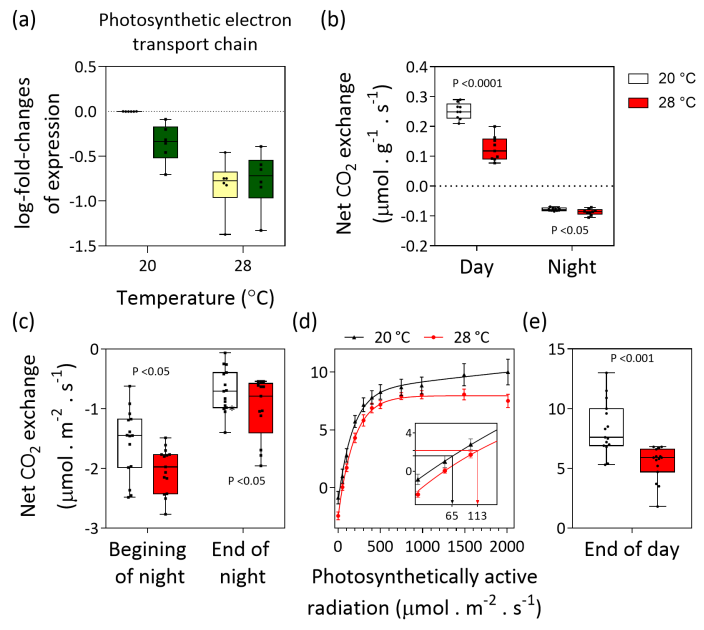

nph_17430_f8.tif 


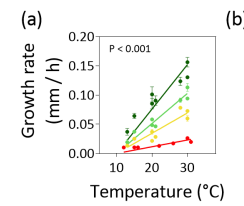

(b)
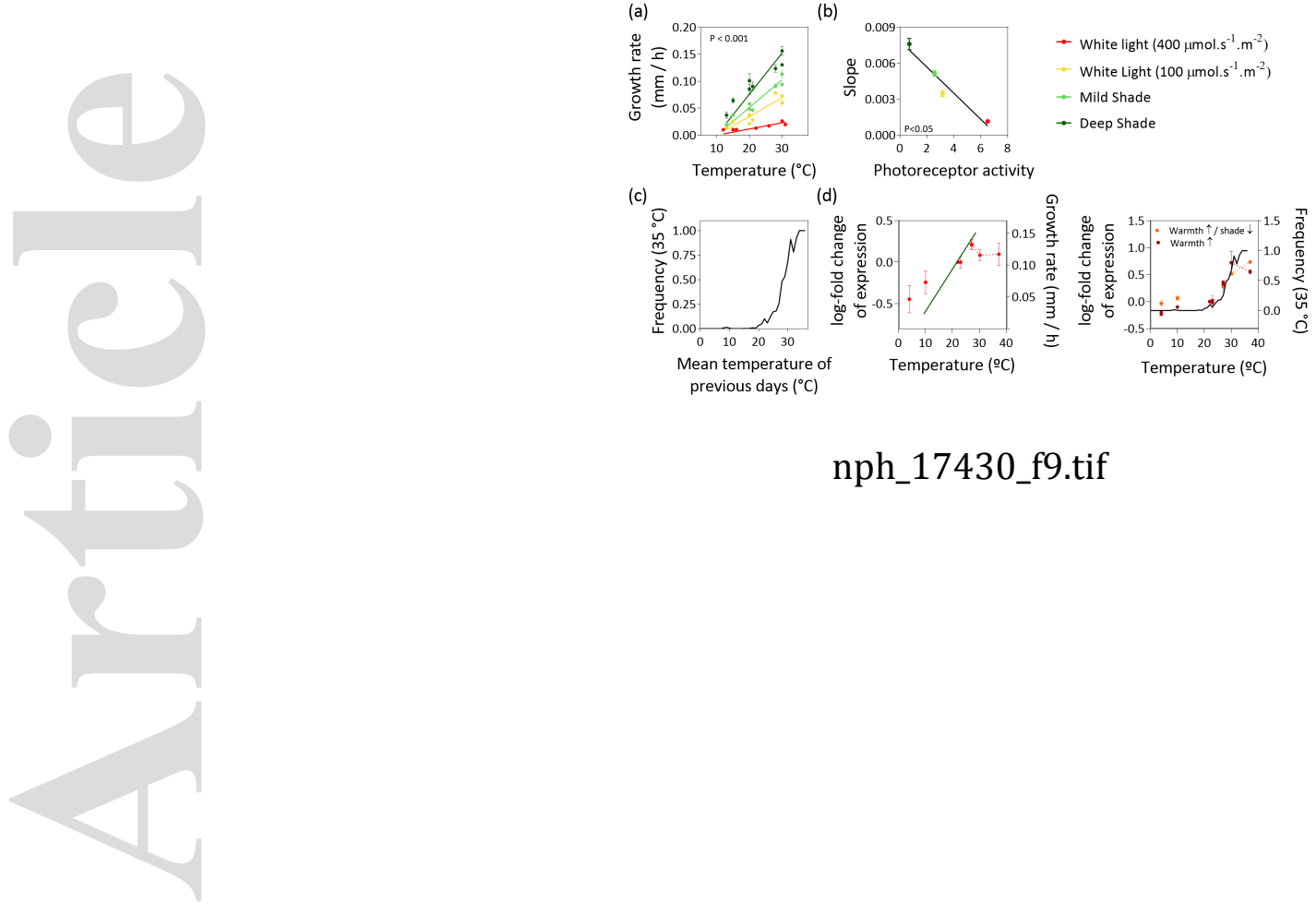

nph_17430_f9.tif

This article is protected by copyright. All rights reserved 